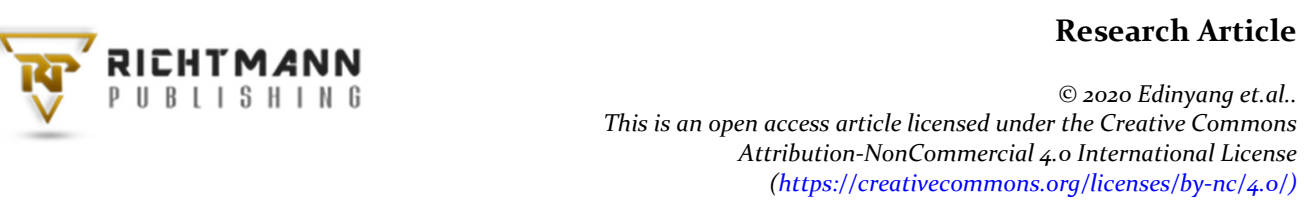

Received: 11 March 2020 / Revised: 28 April 2020 / Accepted: 1 May 2020 / Published: 10 May 2020

\title{
Parental Educational Level and Increase in Street Children in Calabar Metropolis, Cross River State, Nigeria
}

\author{
S. D. Edinyang \\ Frederick Awhen Opoh \\ Edward Ogar Odey \\ Doris Ushie \\ Amina Odugbo Adams \\ Department of Social Science Education, \\ Faculty of Education, University of Calabar, \\ Etagbor, PMB 1115 Calabar 2018, Nigeria
}

Doi: 10.36941/mjss-2020-0031

\section{Abstract}

This study examined the influence of parental educational level on the increase in street children in Calabar metropolis of Nigeria. Single speculation was defined to control the investigation. A writing survey was done dependent on the attribute under investigation. An approved four 16 ounces Likert scale questionnaire was utilized for assessment. The findings revealed that there is a significant influence of parental educational level on the increase in street children in Calabar Metropolis.

Keywords: Parental education, Increase in street children, Illiterate, educated, Discipline

\section{Introduction}

Street children phenomenon is a worldwide social and environmental menace relating to the faulty upbringing, neglect, and poor welfare for a certain group of children around the world. While such children are called "street children" in some parts of the world, they are called "homeless children" in Western Europe i.e. they either live on the street or move and sleep from place to place in either in friends' houses, in market places or uncompleted structures and so on. The issue of street children is a worldwide challenge because no nation across the world is exempted from the challenge of childhood neglect and parental unreadiness that results in abandonment and outright lack of care that drives such children from home into the street to find ways and means of fending for themselves.

Street children are a common eyesore in major cities across Nigeria, not exempting Calabar metropolis, the Cross River State capital. The problem is more prominent and rampant in developing and underdeveloped nations like Nigeria. The influx of street children has gradually become an index capable of being used to measure the level of development in nations across the globe. In other words, there are more "street children" in poor, underdeveloped and developing countries whereas, 
the sight and population of street children in developed countries are limited and under some relative control as a result of the citizens' welfare system of developed nations which at all times cater for and gives attention and support to such children and their parents. Poverty remains a spontaneous voice in the several economic, psychological, as well as physical issues affecting people that needs urgent intervention. Poverty such as homelessness is a major problem in many developing countries. Children are the worst hit in this type of poverty. In reality, it is reported in several kinds of literature that a vast number of children live in streets across the globe and that little or no efforts by their governments to help cater to their needs. However, only a few self-motivated individuals/organizations are attracted to their plights. This trend was further attributed to the lukewarm attitude of government at all spare and therefore needs urgent attention.

It is somehow difficult to give a specific and acceptable definition for the term "street children". Differences in the definition are because of the contrasts in the different hypothetical and ideological foundations of childhood specialists, as well as differences in time and place. Even though this does not imply that there are no broad systems or ideas that specialist can concede to and allude to, the definition and portrayal of this phenomenon have been founded on shifted modes and approaches WHO (2004) categorized street children into four: children living on streets; children who have left their immediate families and now live in streets, lodgings, shelter homes, or abandon buildings; kids who have feeble or pitiful relations with their families, and whose conditions obliged them to experience the night outside their homes; and kids living in halfway houses (midway homes), who are at risk for being desperate.

The United Nations Educational, Scientific, and Cultural Organization (UNESCO) (2006) explained road kids as "Kids with cut off family ties, who have discovered the road their solitary home; the road is the place they remain day by day; whom all face similar risks, for example, getting associated with medications or prostitution, and their essence in the boulevards gives them a feeling of opportunity." Similarly, UNICEF (2015), thought about three types of road kids: youngsters who invest the majority of their energy in the road, yet who routinely return to their homes; kids who work in the road; kids who have fled from their families and live alone in the road; kids from street families; children who live with their families in the street, and children who are resident in streets.

Again, Lusk (2008) categorized and developed three groups of street children. Each group has specific psychological attributes. (i) The independent street workers. These are otherwise referred to as street survivals; in that, they survive from their daily hustle. These types have poor school attendance and a higher level of delinquency because of the several activities being involved in for survival. (ii) The poor street hawkers that will likely return to their families at night. They are usually on the street to market their goods and support their families. They are likely to attend school and not be delinquent. (iii) The third set of street children are those who reside with their families in the street because of poverty.

These "street children" definitions are conditioned by various principles; such as, residency, family relations, activities that keep them longer on the street. These defining criteria can also be recategorized into more detailed conditions. For instance, family relations - there are, children, having weak contact with their family, children having daily contact with their, and children with no family contact at all.In India, they are referred to as pavement dwellers (Patel, 1983), whereas in Nigeria they are the offspring of destitute families. At long last, some youngsters have severed contact with their families. They are full-time street residents and are the "real" street children.

Estimating the statistical data of "street children"e across the world, in continents or even within nations, has been an uphill task over the last two and a half decades. Between 1989 and 2005, UNICEF estimated the number of street children or homeless children as running into tens of millions across the world but quoted in each case a figure of 10omillion (UNICEF, 2015). Considering a more feasible and realistic growth in statistical data, a deteriorating level of the economic and financial situation around the world in the last decade with great intensity in underdeveloped and developing countries; which resultantly worsened the incidence of extreme poverty and hunger in developing countries, it is only logical to expect that a worsening poverty incidence across the developing world will stimulate 
an increase in the menace of parental irresponsibility resulting in an increase in the number of street children particularly in developing countries like Nigeria and Cross River State.

The list below is a random sample of the outlook of the incidence of the number of street children in each of the listed nations which is a reflection of the level of development and the effect of poverty and the living standard of the people.

\begin{tabular}{|l|c|l|c|}
\hline Indian & $\mathbf{1 8}$ million & Kenya & $\mathbf{2 5 0 , 0 0 0 - 3 0 0 , 0 0 0}$ \\
\hline Russia & 7 million & Congo & $\mathbf{2 5 0 , 0 0 0}$ \\
\hline Nigeria & 7 million & Morocco & $\mathbf{3 0 , 0 0 0}$ \\
\hline Egypt & 1.5 million & Brazil & $\mathbf{2 5 , 0 0 0}$ \\
\hline Pakistan & 1.5 million & Germany & $\mathbf{2 0 , 0 0 0}$ \\
\hline Philippines & 1.5 million & Vietnam & 80,000 \\
\hline
\end{tabular}

Nigeria is the most populous nation in Africa; exceptionally endowed by God in rich land, mineral, resources (oil, gold, coal etc.), environmental and beautiful weather opportunities for farming and an array of human capital resources to manage the other resources; Despite the magnitude of resources, corruption and leadership challenges has denied the citizenry, particularly the youth and children the opportunity to enjoy the dividends of good life, good education, good health and the enviable standard of living God has provided for the average Nigerian child; so majority of the 'street children' in Nigeria are not expected to undergo the kind of hardship they undergo; if we can put corruption and bad leadership behind us, Nigeria should not have any of her children except the lazy ones, identified as street children India does not have a half of the resources, Nigeria has, but Indians strives for economic supremacy through good leadership and hard work, yet with her very limited resources, it is recording an unprecedented economic growth and development, but the lack of discipline to control its ever growing population has negated the ability of India to reap the fruit of hard work for economic growth so it has the largest population of "street children" all over the world.

On the other hand, Nigeria is endowed with everything she requires for economic success and exceptional good living standard, but Nigeria has corruption and bad political leadership as obstacles to its economic growth and development, so Nigeria's resources have continually been abused, misused and stolen by a few greedy, selfish, irresponsible people who continually use stolen money to perpetuate themselves in political office, instituting corruption as the national symbol and instrument of rulership since independence, so Nigeria notwithstanding its huge and diverse resources, has a huge army of street children. What an irony.

No one knows the exact reasons for children becoming "street childrene. Certain common factors could be linked with reasons for the influx of street children cutting across regional, economic and developmental level, these could include- Child abandonment by poor families, family inability to feed their children and provide their needs for education, clothing, and the HIV/AIDS scourge in Africa which has killed many parents and turned their children to orphans. Children may choose to live in the streets because of parent's maltreatment or neglect, or because their parents cannot provide them with basic needs of life (food, shelter, education, clothing, etc). Many children work and stay in the streets so that their earnings could be used to support their poor families. The society is made up of individuals summed up in families the basic purposes behind destitution or breakdown of homes and families might be political, economic, social, or ecological or a mix of the above factors. The "World Health Organization" (WHO) in 1993, the report offered the following causes of the phenomenon: Family breakdown, armed conflict in nations or between nations, poverty, disaster (ecological, or man-made), starvation, assault, sexual exploitations, mistreatment, urbanization and congestion, separation through migration, exclusion or being repudiated

Many variables have received consistent attention among researchers as it relates to an increase in street children. These variables which include but not limited to gender, age, family educational background, family socio-economic background, marital status, family size, and ethnicity have been examined as to the existence of difference, association, and correlation to increase in street children. 
Based on previous researches, there were several compelling reasons to expect that parental education may serve to foster a child's decision to move to the street for daily survival.

The issue of kids staying and working by the road looks like a new phenomenon in Calabar Metropolis. High levels of illiteracy despite institutional efforts at ameliorating it, still exist in the country, however, many of these illiterate population are found in streets. In that the illiterate parents still wallowing in poverty, bringing up their children in the same illiterate pattern. Their poverty status tends to affect the values they attach to education and therefore rub-off on the mindsets of their children. Families residing in the street do so because they are poor. Therefore, for them, schooling is a rare option because of their inability to providing the necessary educational requirements for their children. This is why many street children are school drop-outs, and their parents/families are the perpetuating factors for these happenings (Wernham, 2011).

Ukap (2018) investigated the difference between the educational background of parents and students' tendencies to become street children in Delta State, Nigeria. The population for this study comprised all accessible street children in Delta state. The sample consisted of 390 children purposively selected from seven Local Government Areas. Quantitative data for the study were derived using a structured questionnaire. The instrument was subjected to face and content validation using expert judgments. The reliability of the study was achieved using a test-retest procedure, with a coefficient figure at $\mathbf{0 . 7 2}$. the actual variables were statistically analyzed using a one-way analysis of variance. The result revealed a significant impact on parents' education with high educational background and the ability to prefer the benefits of the street. The study outcome, however, suggested that the building of adult education centres be strongly recommended in government educational policy. In that, the school curriculum should be equipped to meet up with current innovations and practices in achieving adult learning especially among the very illiterate adults

According to Dornbusch, Ritter, Leiderman, Roberts, and Fraleigh (2017), parenting style as a major factor in child upbringing is strongly influenced by the parents' levels of education. The family is fondly reported is the first port for a child's socialization. This, therefore, implied that parents that are poorly educated portray attitudes that affect their children's behaviour. Likewise, educated parents are less strict and more permissive in bringing out the needed value in their children. Accordingly, White (1982) and Mullis and Jenkins (2010), proposed that parental education shows a strong correlation to students' tendencies to become street children. Other researchers have debated the correlation between parents' educational attainment and students' tendencies to become street children.

Ayodele, Aremo, and Abogan (2010) examined family characteristics and an increase in street children in Nigeria. The study employed the survey research design that made use of the questionnaire and focused interviews for data collection. Data were collected from 110 children comprising of hawkers, and those who stay permanently in the street. Simple random sampling techniques were utilized and the data were analyzed using a simple linear regression technique. The result revealed that parents' educational level positively affects children's decision to misbehave and seek for freedom, which causes them to end in the street.

Melby and Conger (2016) reported that parental educational attainment links positively to parenting and children misbehaviour. Stevenson and Baker (2017) proposed that literate mothers with a good predisposition to current information about the school are more likely than illiterate mothers to discuss their children's problems. It was further revealed that literate mothers' expectation levels are higher and they have more demands for good behaviour for their children.

Ordinarily, a child is supposed to be cared for by giving them the five basic needs as shelter, food, clothing, security, and love. Thus, the child being found roaming the street is a mere denial of these basic needs and a denial of their basic rights. The Consortium for Street Children stressed that children have so many risk factors and that children found in streets are readily exposed to violence, particularly by individuals who should have protected them.In many countries, police particularly harass these sets of children through beating, torturing, sexual exploitations, forcefully, propel them 
to pay money in exchange for security or release from detainment, and a good number of these children are even executed by police officers. In most cases, the perpetrators of this crime against these children are rarely brought to justice (Fahmi, 2010).

A few studies have compared the influences of mothers' and fathers' education on child development which instills discipline and determines the tendencies to move to the street, findings have revealed dissimilar and often inconsistent results. In a report by Aslam and Kingdon (2012), only the mother's education was a significant predictor of a disciplined child. While Semba, De Pee, Sun, Sari, Akhter, and Bloem(2018) revealed that both parents' education levels are equally protective and instill discipline in a child. The contrasting findings of these studies show the relationship between parental education and children's tendencies to move to the street is far from clear.

\section{Methodology}

The survey research design was considered most suitable for the study. The sample of the study comprised 98 street children who reside in Zoo Garden by Mary Slessor, First bank by Marian road, Calabar South, and IkotIshie street. The area of the study is Calabar Metropolis, which comprised Calabar South and Calabar Municipality Local Government Areas. This study adopted the accidental sampling technique. The data tool that was utilized for information assortment was a poll. Every item evoked data from respondents on a four-point adjusted Likert scale, Strongly Agree (SA) 4 focuses, Agree (A) 3 focuses, Disagree (D) 2 focus, and Strongly Disagree (SD) 1 point. The hypotheses were analyzed using One-way Analysis of variance (ANOVA) statistics at 0.05 level of significance (i.e. 95\% confidence interval) with the help of statistical package for social sciences (SPSS) version 20.

\section{Results and Discussion}

The hypothesis states that parental educational level has no significant influence on the increase in street children. The independent variable in this hypothesis is parental education level which is categorized into Non-formal education, FSLC/SSCE, First degree, and above while the dependent variable increases in street children. One way analysis of variance (ANOVA) was utilized in the analysis of the information gathered from respondents. The result is as displayed in the first table.

The outcome in Table one revealed that the mean score obtained by the 59 subjects whose parents have no formal education was 26.02 with a standard deviation of 5.99 is greater than the mean score of 25.02 with a standard deviation of 4.20 obtained by the 27 subjects whose parental education level is FSLC/SSCE and this is also greater than the mean score of 24.97 with a standard deviation of 4.49 obtained by the 12 subjects whose parents have obtained a first degree and above. This implies that the lower the parental educational level of the children, the higher the increase in the number of street children in Calabar Metropolis of Cross River State and vice versa.

The result of the analysis as presented in Table 1 showed that the determined F-estimation of 11.320 is more prominent than the basic F-estimation of 3.11 at 0.05 degree of noteworthiness with 96 degrees of freedom. This implied that the null hypothesis was rejected. Therefore, parental education level has a significant influence on the increase in street children in Calabar metropolis of Cross River State, Nigeria.

Table 1: One-way analysis of variance of the influence of parental educational level on increase in street children

\begin{tabular}{lccc}
\hline Educational level & $\mathrm{N}$ & $\bar{X}$ & SD \\
\hline No formal education & 59 & 26.02 & 5.99 \\
FSLC/SSCE & 27 & $\mathbf{2 5 . 0 2}$ & 4.20 \\
First degree and above & 12 & 24.97 & 4.49 \\
Total & 98 & 76.01 & $\mathbf{1 4 . 6 8}$ \\
\hline
\end{tabular}




\begin{tabular}{lccccc}
\hline Source of variance & SS & Df & MS & F-ratio & Sig. \\
\hline Between groups & 13.583 & 2 & 6.791 & & \\
Within groups & $\mathbf{2 0 1 6 . 2 8 2}$ & 95 & 21.224 & & \\
Total & $\mathbf{2 0 2 9 . 8 6 5}$ & 97 & & & .327 \\
\hline
\end{tabular}

Significant at 0.05; $\mathrm{df}=96 ;$ Critical $-\mathrm{F}=3.11$

Since the result of this analysis was significant, a Fisher's protected t-test analysis was carried out to determine where the significant difference was highest among the various categories of parental educational level in the study. The result of this analysis is presented in Table 2.

The result of the Fisher's protected t-test analysis as presented in Table 2 revealed that the mean score in an increase in street children among the subjects whose parents have no formal education differ significantly in an absolute sense when compared with that of those whose parents have FSLC/SSCE in favour of those whose parents have FSLC/SSCE (MD = 1.00; $\mathrm{p}<.05)$ and also differ significantly when compared with the mean score of those whose parents have acquired first degree and above in favour of those whose parents have acquired first degree and above (MD $=1.05^{*} ; \mathrm{p}<.05$ ). The result finally revealed that the mean score an increase in street children among the subjects whose parents have FSLC/SSCE differ significantly in an absolute sense when compared with the mean score of those whose parents have acquired first degree and above in favour of those whose parents have acquired first degree and above $\left(\mathrm{MD}=0.05^{*} ; \mathrm{p}<.05\right)$. Based on these, the source of the difference was basically from all the various family structure categories but was more from those whose parents have acquired first degree and above.

The result of this study agrees with the result of Wernham (2011) which stated That high level of illiteracy despite institutional efforts at ameliorating it, still exist in the country, however, many of these illiterate population are found in streets. In that the illiterate parents still wallowing in poverty, bringing up their children in the same illiterate pattern. Their poverty status tends to affect the values they attach to education and therefore rub-off on the mind-sets of their children. Families residing in the street do so because they are poor. Therefore, for them, schooling is a rare option because of their inability to providing the necessary educational requirements for their children. This is why many street children are school drop-outs, and their parents/families are the perpetuating factors for these happenings. The result of the study is also in tandem with Dornbusch, Ritter, Leiderman, Roberts, and Fraleigh (2017) which purported that parenting style as a major factor in child upbringing is strongly influenced by the parents' levels of education. The family is fondly reported is the first port for a child's socialization. This, therefore, implied that parents that are poorly educated portray attitudes that affect their children's behaviour. Likewise, educated parents are less strict and more permissive in bringing out the needed value in their children. Accordingly, White (1982) and Mullis and Jenkins (2010), proposed that parental education shows a strong correlation to students' tendencies to become street children. Other researchers have debated the correlation between parents' educational attainment and students' tendencies to become street children.

Table 2: Fisher's protected t-test of the influence of parental educational level on increase in street children

\begin{tabular}{llcc}
\hline Parental educational level & Joint & Mean difference & Significant \\
\hline No formal education & FSLC/SSCE & 1.00 & .000 \\
& First degree & $1.05^{*}$ & .003 \\
FSLC/SSCE & No formal education & $-1.00^{*}$ & .002 \\
& First degree & $0.05^{*}$ & .042 \\
First degree & No formal education & $-1.05^{*}$ & .000 \\
& FSLC/SSCE & $-0.05^{*}$ & .040 \\
\hline
\end{tabular}

${ }^{*}$ Mean difference is significant at 0.05 


\section{Conclusion}

The purpose of this study was to investigate and present results on demographic variables and an increase in street children in Calabar Metropolis of Cross River State. In accordance with the measurable finding got from this investigation, it was along these lines inferred that: there was a noteworthy impact of parental educational background on increase in street children in Calabar metropolis. And that there was a significant influence of family structure on an increase in street children in Calabar Metropolis. Street children phenomenon is a major challenge to the residents of Calabar metropolis, the rising inquiries on how best these challenges are handled by the society has flooded many studies. However, these concerns had also drawn the attention of several human rights activists, governmental policy offices, wellbeing agencies (internal and international agencies) in procuring lasting solutions to the incidence of street children. However, these solutions are further plagued by the homeless situations of many families as a result of poverty. This study, therefore, concludes that the family is the main factor in the street children phenomenon in Calabar, and that intervention programmes targeting the family will curb the menace it poses.

\subsection{Recommendations}

It is recommended as follows;

1. That the zeal for adult education should be encouraged through governments' initiative at equipping school curriculum to accommodate adult literacy programmes. This will help educate illiterate parents and help alleviate the incidence of street children in Calabar metropolis.

2. Home visiting intercession activities that screen youngster improvement and give counsel, backing, and referral to families with road kids ought to start, as opposed to simply reintegration or repatriation or reunification of these kids with their families. This can be truly outstanding and most down to earth strategies for realizing a noteworthy decrease in youngster misuse and disregard in the family set up that has been accused to be among different variables that make kids flee from their homes. This will likewise squeeze the family foundation to assume liability and maintain estimations of the family and kids.

\section{References}

Aslam, M. \&Kingdon, G. G. (2012). Parental education and child health: understanding the pathways of impact in Pakistan. World Development, 40,32.

Awatey, S. (2014). Assessing the Effects of Streetism on the Livelihood of Street Children: A Case Study of Kumasi (in Ghana). Research on Humanities and Social Sciences, 4(9), 165-174.

Ayodele, H., Aremo, K. \& Abogan, D. (2010). The Lived Experiences of Children Living on the Streets of Hillbrow. Curationis, $38(1), 8$.

DeBaryshe, B. D., Pattersoon, G. R., \&Capaldi, D. M. (2013). A performance model for academic achievement in early adolescent boys. Developmental Psychology, 29, 795-804.

Dornbusch, S. M., Ritter, P. L., Leiderman, P. H., Roberts, o. F., \&Fraleigh, M. J. (2017). The relation of parenting of style to adolescent school performance. Child Development, 58, 1244-1257.

Fahmi, M. (2010). Street Children: A Civilization Tragedy in the Third Millennium, Alexandria, The Modern University Office, 33 .

Lusk, M. (2008). Street children of Rio de Janeiro. International Social Work, 35,293- 305.

Melby, J. N., \& Conger, R. D. (2016). Parental behaviours and adolescent academic performance: A longitudinal analysis. Journal of Research on Adolescence, 6, 133-137.

Mullis, I. V. S. \& Jenkins, L. B. (2010). The reading report card, 1971-88: Trends from the nation's reading report card (Report No. 19-R-o1). Princeton, NJ: National Assessment of Educational Progress, Educational Testing Service.

Patel, A. (1983). An Overview of Street Children in India. Covenant House, New York. 
Semba, R. D., De Pee, S., Sun, K., Sari, M., Akhter, N. \&Bloem, M. W. (2018). Effect of parental formal education on the risk of child stunting in Indonesia and Bangladesh: a cross-sectional study. Lancet, 371,322-8.

Stevenson, D., \& Baker, D. (1987). The family-school relation and the child's school performance. Child Development, 58, 1348-1357.

Ukap, E. (2014). The influence of parents' educational background and students influx in the street. An unpublished PGD project. National Teachers Institute.

UNICEF: (2015). The state of the world's children 2008 report, UNICEF: oxford university press.

Wernham, M. (2011). Consortium on Street Children, Background Paper on Street Children and Violence.

White, M. A. (2012). The Problem of Street Children: Case Study of Sargodha City. American International Journal of Contemporary Research, 2 (2), 194-197.

World Health Organization (2004). The rapid assessment and response guide on psychoactive substance use and especially vulnerable young people, Geneva. 